\title{
O SISTEMA CARCERÁRIO NO BRASIL
}

THE PRISON SYSTEM IN BRAZIL

\author{
EL SISTEMA PRISIONERO EN BRASIL
}

\author{
Robinson Daniel Estrella ${ }^{1}$ \\ Fernanda dos Santos Duarte ${ }^{2}$ \\ Jacira Maria Muller Nogueira ${ }^{3}$ \\ Luis Eduardo Machado Moraes ${ }^{4}$ \\ Crisciani Lago $^{5}$ \\ Diogo Silva de Quevedo 6
}

RESUMO: A finalidade deste artigo é buscar conhecer como funciona o sistema carcerário brasileiro buscando o saber do que é prisão e pena e apresentar um breve relato de um de seus maiores problemas a superlotação. Assim este artigo teve como objetivo buscar o saber o que é a Prisão e conhecendo os tipos de estabelecimentos prisionais citados na Lei de Execução Penal, o conhecimento do que é Pena e suas modalidades citadas pelo Código Penal Brasileiro e apontar a problemática da Superlotação carcerária no Brasil que é um dos grandes problemas que impede a ressocialização.

Palavras-chave: Prisão. Pena. Superlotação.

ABSTRACT: The purpose of this article is to get to know how the Brazilian prison system works, seeking to know what prison and punishment is, and to present a brief account of one of its biggest problems: overcrowding. So this article aimed to seek to know what the Prison is and knowing the types of prison establishments mentioned in the

\footnotetext{
${ }^{1}$ Superior de Tecnologia em Gestão Pública - UNIFRAN. Educação Física - UlBRA. E-mail: jscestrella@gmail.com.

${ }^{2}$ Psicologia-PUCRS. E-mail: duartefe@yahoo.com.br.

${ }^{3}$ Direito-Unilasalle Canoas. E-mail: jaciramm@hotmail.com.

4 Educação Física- URCAMP. E-mail:viniciusrafaeltudo@hotmail.com.

5 Engenharia Civil - ULBRA. E-mail: crisciani.lago@gmail.com.

${ }^{6}$ Administração-IERGS. E-mail:diogoquevedo@hotmail.com.
} 
Penal Execution Law, the knowledge of what is Penal and its modalities mentioned by the Brazilian Penal Code and to point out the problematic prison overcrowding in Brazil, which is one of the major problems that prevent resocialization.

Keywords: Prison. Feather. Over crowded.

RESUMEN: El propósito de este artículo es conocer cómo funciona el sistema penitenciario brasileño, buscando saber qué es la prisión y el castigo, y presentar un breve relato de uno de sus mayores problemas: el hacinamiento. Así, este artículo tuvo como objetivo buscar conocer qué es la Prisión y conocer los tipos de establecimientos penitenciarios mencionados en la Ley de Ejecución Penal, el conocimiento de qué es la Pena y sus modalidades mencionadas por el Código Penal brasileño y señalar la problemática del hacinamiento penitenciario. en Brasil, que es uno de los mayores problemas que impiden la resocialización.

Palabras clave: Prisión. Pluma. Lleno de gente.

\section{INTRODUÇÃO:}

O sistema Prisional Brasileiro atualmente passa por constantes dificuldades, considerando que a pena de prisão tem por objetivo a proteção da sociedade contra o crime, entende-se também que esse objetivo só pode ser alcançado se quando, durante o processo de reclusão, ao preso sejam proporcionadas condições mínimas no qual ele compreenda que após o cumprimento da pena, ao reingressar na sociedade. Desta forma, o preso terá como direito as condições que possibilitem o seu processo de ressocialização. Assim buscou-se o conhecimento do de que de fato é uma Prisão e como está é caracterizada, como são os estabelecimentos prisionais previstos em lei, o que é Pena e suas modalidades de como devem ser cumpridas e a problemática da superlotação apontando alguns dos problemas que trazem consigo, pois a prisão é um mal necessário, mas que deveria ser melhor trabalhado a ressocialização do apenado.

Esse artigo trata-se de uma pesquisa bibliográfica, uma vez que a natureza das fontes investigadas serão os livros e sites eletrônicos.

\section{DEFINIÇÃO DE PRISÃO}

Prisão segundo dicionário Aurélio:

I - Ato de prender. 
2- Captura

3 - Local onde se cumpre uma pena de detenção

4 - Pena de detenção que um réu tem de expiar na cadeia

5-Estado de quem se acha preso

6 - Qualquer coisa que restringe a liberdade

7 - Laço, vínculo, cadeia ...

Segundo Bittencourt (1993), a prisão é concebida modernamente como um mal necessário, sem esquecer que guarda em sua essência contradições indissolúveis.

A prisão, em sentido jurídico, é a privação da liberdade de locomoção, ou seja, do direito de ir e vir, por motivo ilícito ou por ordem legal. Entretanto, o termo tem significados vários no direito pátrio pois pode significar a pena privativa de liberdade ("prisão simples" para autor de contravenções; "prisão" para crimes militares, além de sinônimo de "reclusão" e "detenção “), o ato da captura (prisão em flagrante ou em cumprimento de mandado) e a custódia (recolhimento da pessoa em cárcere). Assim, embora seja tradição no direito objetivo o uso da palavra em todos esses sentidos, nada impede se utilize os termos "captura" e "custódia", com os significados mencionados em substituição ao termo "prisão".(MIRABETTE,2003,p.359)

Com a intenção de punir e prevenir novos delitos a prisão é uma sanção imposta pelo Estado aos indivíduos que praticaram delitos passíveis de punição e restritivas de liberdade.

O Sistema prisional brasileiro tem como objetivo a ressocialização e a punição da criminalidade. Assim sendo, o Estado assume a responsabilidade de combater os crimes, isolando o criminoso da sociedade, através da prisão, o mesmo é privado da sua liberdade, deixando de ser um risco para a sociedade.

A falência de nosso sistema carcerário tem sido apontada, acertadamente, como uma das maiores mazelas do modelo repressivo brasileiro, que, hipocritamente, envia condenados para penitenciárias, com a apregoada finalidade de reabitá-lo ao convívio social, mas já sabendo que, ao retornar à sociedade, esse indivíduo estará mais despreparado, desambientado, insensível e provavelmente, até mais violents em relção ao que o conduziu ao cárcere.(MIRABETTE, 2008, p.89) 
A Lei de Execução Penal - LEP a partir do seu Art.87, especifica os tipos de estabelecimentos prisionais, que são:

- Penitenciária - é a unidade prisional destinada aos condenados qu cumprirão pena em regime fechado;

- Colônias agrícolas/industriais - são destinadas aos presos em regime semi-aberto;

- Casas de albergado - são destinadas aos presos em regime aberto:

- Hospital de custódia - destinado aos indivíduos com problema mental que cometeram algum tipo de crime, cumprindo medida de segurança;

- Cadeia pública - destina-se ao recolhimento de presos provisórios

\title{
2.1 Definição de Pena
}

Segundo Bueno(2002, p.584) s.f. "punição imposta pelo Estado ao contraventor ou delinquente por um delito cometido; punição; sofrimento; desgraça”. O termo pena provém do grego "poiné", e no lati "poema”, representando em ambas as línguas: aflição, castigo e uma forma de reprimir e prevenir delitos, o que pressupõe uma ação educativa e corretiva dos infratores(CALDAS; CARLS,2009)

Em relação ao poder do ente público é válido destacar que a "pena é a consequência natural imposta pelo Estado quando alguém pratica uma infração penal, abrindo a possibilidade para o Estado fazer valer o jus puniend" (BOTELHO,2012,P.3)

\begin{abstract}
A pena s caracteriza por ser personalíssima, ou seja, pela impossibilidade de passar da pessoa do delinquente; submete-se ao princípio da legalidade, não havendo pena sem lei anterior que a defina; é inderrogável, não podendo deixar de ser aplicada diante de condenação; proporcionalidade, que diz respeito ao equilíbrio entre a infração cometida e a sanção aplicada(BOTELHO, 2012, p.3)
\end{abstract}

A Pena tem além do caráter retributivo, tendo em vista que a sanção penal consiste em um "mal" imposto ao infrator da lei, em virtude dessa violação, ela também assume uma posição preventiva e ressocializadora.

É no Código Penal brasileiro que está contido as formas de sanções, as características contidas na lei penal além das modalidades de condutas e penas a serem aplicadas em nosso país. 
No Art.32 do Código Penal brasileiro estabelece as modalidades de penas aplicáveis, que se caracterizam em: privativas de liberdade, restritivas de direito e penas de multa.

O Art.33 do Código Penal Brasileiro especificam as modalidades de penas, a seguir: A pena de reclusão deve ser cumprida em regime fechado, semi-aberto ou aberto. A de deenção, em regime semi-aberto, ou aberto, salvo a necessidade de transferência a regime fechado.

Io- Considera-se :

a) regime fechado a excução da pena em estabelecimento de segurança máxima ou média;

b) regime semi-aberto a execução da pena em colônia agrícola, industrial ou estabelecimento similar;

c) regime aberto a execução da pena em casa de albergado ou estabelecimento adequado."

Sobre a finalidade da pena, Oliveira afirma que,

“ O desejado sentido ressocializador da pena, na verdade, configura apenas um fantástico discurso retórico para manter o sistema, o que, na realidade, traduz um evidente malogro, um desperdício de tempo para o preso e um gasto inútil para o Estado, que retira da sociedade um indivíduo por apresentar comportamento desviante e o transforma em um irrecuperável, pois a reincidência atinge o alarmante índice de mais de setenta por cento no país.(OLIVEIRA, 1996,p.233)

A pena tem além de caráter retributivo, tendo em vista que que consiste em um mal necessário imposto ao infrator da lei.

Dede a origem até hoje, porém a pena sempre teve o caráter predominante de retribuição, de castigo, acrescentando-se a ela uma finalidade de prevenção e ressocialização do criminoso. A retribuição e a prevenção são faces da mesma moeda e, como acentuava Everardo da Cunha Luna, "retribuição, sem prevenção, é vingança; a prevenção, sem a retribuição, é desonra”. (MIRABETT, 2003,p.245)

\subsection{Superlotação Prisional e Seus Problemas}

Segundo o Ministério da Justiça(2017) há 726.354 pessoas privadas de liberdade no Brasil.

A superlotação prisional no Brasil é diversa do artigo 85 da lei de Execução Penal, o qual prevê, "o estabelecimento penal deverá ter lotação compatível com a sua estrutura e finalidade". 


\section{Referente à superlotação prisional Camargo}

As prisões encontram-se abarrotadas, não fornecendo ao preso a sua devida dignidade. Devido à superlotação muitos dormem no chão de suas celas, às vezes no banheiro, próximo a buraco de esgoto. Nos estabelecimentos mais lotados, onde não existe nem lugar no chão, presos dormem às grades das celas ou pendurados em rede.

Nas condições atuais as prisões brasileiras não têm êxito em relação à redução da criminalidade, sabendo-se que esse é seu principal objetivo, mais isso não é uma realidade. Percebe-se isso, pelo fato do crescimento da reincidência de crimes e prisões.

Vieira afirma que:

(...) as unidades prisionais brasileiras não oferecem uma estrutura nem física, nem humana, o sistema precisa de mudanças emergenciais para poder acolher os detentos numa forma mais humana. E assim tentar ressocializar o preso de forma mais rápida. (VIEIRA, 20II, p.II7)

Existem variadas formas de controle social, que o Estado utiliza para "moldar" e punir os indivíduos que se desviam e se recusam a obedecer às regras impostas.

Como diz Ferreira:

A punição é imposta ao contraventor ou delinquente, em processo judicial de instrução contraditória, em decorrência de crime ou contravenção que tenha cometido com o fim de exemplá-lo e evitar a prática de novas infrações. (FERREIRA,1989, p.1070)

A primeira proposta do Sistema Prisional é a punição do infrator, e a segunda a ressocialização desse indivíduo na tentativa de reintegrá-lo ao convívio social, na condição de cidadão totalmente recuperado. Mais o que se pode observar é a falibilidade do sistema, no tocante em que constatamos a grande quantidade de reincidências. Quando livres, os ex detentos regressam a sociedade, por vezes mais perigosos e revoltados do que antes, retornando as suas práticas delituosas, fazendo da reincidência um ciclo sem fim. Sobre o Sistema carcerário:

A falência de nosso sistema carcerário em sido apontada, acertadamente, como uma das maiores mazelas do modelo repressivo brasileiro, que, hipocritamente, envia condenados para penitenciárias, com a apregoada finalidade de reabilitá-lo ao convívio social, mas já sabendo que, ao retornar à sociedade, esse indivíduo estará mais despreparado, desambientado, insensível e, provavelmente, com maior desenvoltura para a prática de outros crimes, até mais violentos em relação ao que o conduziu ao cárcere.(MIRABETTE,2006) 
Segundo Costa,20Ir A falta de investimento público é um grande fator que impede a solução da superlotação. Há necessidade de construção de novos estabelecimentos no Brasil com infraestrutura capaz de proporcionar a ressocialização do condenado e que o mesmo tenha condições de sobrevivência de forma digna e humana. Este porém, não é a única solução existente para resolver o problema da superlotação do sistema prisional.

SENNA (2008) diz que temos depósitos humanos, escolas de crime, fábrica de rebeliões. Não podemos mais "tapar o sol com a peneira", e fingir que o fato em questão não nos diz respeito. O Brasil possui um dos maiores sistemas prisional do planeta e são notórias as condições cruéis e desumanas de cumprimento de pena em nosso país.

Deste modo, utilizando-se como referência o pensamento de João Faria Junior podemos elencar como os principais problemas do sistema carcerário brasileiro, os seguintes males:

I A ociosidade - Apenas 5\% dos encarcerados brasileiros trabalham ;

2 Baixíssima remuneração, não observando o estipulado mínimo de $3 / 4$ determinada pela LEP

3. A superlotação - a falta de vagas ultrapassa marcas absurdas, sem contar os mandados de prisão não cumpridos. A superlotação é a principal causa das rebeliões nas prisões.

4.A promiscuidade - é consequência da superlotação, por se reunirem numa mesma cela um amontoado de pessoas das mais variadas espécies.

5. A formação de grupos mafiosos que são comandados por líderes que exercem poder de dominação sobre os demais presos, com objetivo de adquirir armas, bancar o jogo de azar, tráfico de drogas, tabaco e álcool, cobrar por proteção e violentar sexualmente outros presos.

6. Fugas, motins, greves, violência, privilégios de certos presos e discriminação de outros, corrupção dos funcionários, falta de capacidade administrativa para gerenciar o estabelecimento prisional, falta de verbas, etc."

Prisões superlotadas são perigosas já que elevam as tensões internas dos estabelecimentos, transformando presídios em bombas relógio.

Segundo Ottoboni(200I) o delinquente é condenado e preso por imposição d sociedade, ao passo que recuperá-lo é um imperativo de ordem moral, do qual ninguém 
deve se escusar. A sociedade somente se sentirá protegida quando o preso for recuperado. A prisão existe por castigo e não para castigar.

Ainda expressa MIRABETTE que:

\begin{abstract}
A falência de nosso sistema carcerário tem sido apontada, acertadamente, como uma das maiores mazelas do modelo repressivo brasileiro, que, hipocritamente, envia condenados para penitenciárias, com a apregoada finalidade de reabilitá-lo ao convívio social, mas já sabendo que, ao retornar à sociedade, esse indivíduo estará mais despreparado, desambientado, insensível e, provavelmente com maior desenvoltura para a prática de outros crimes, até mais violentos em relação ao que o conduziu ao cárcere.
\end{abstract}

\title{
CONCLUSÃO
}

Pode se concluir que o sistema carcerário tem que ser renovado, para que a proposta inicial pela qual foi implantado possa estar sendo aplicada ressocializando o apenado, pois a pena restritiva de liberdade não deve ser apenas uma punição, mas um meio de criar condições para que este apena volte melhor para a sociedade e não o deixando mais apto ao crime. Acabar com a superlotação traz mais benefícios para todos, pois tem menos chances de ocorrem rebeliões de transmissões de doenças e de ser uma "escola do crime”. Dessa forma deve ser reformulado o sistema penitenciário, visto que, esse tem uma boa proposta, mas deve ser reformulada sua aplicação, pois assim estará assumindo um compromisso de melhoria com a sociedade no geral.

\section{REFERÊNCIAS BIBLIOGRÁFICAS:}

BItTenCOURT, César Roberto. Falência da Pena de Prisão. São Paulo: Revista dos Tribunais, 1993.

BOTELHO, Jéferson. Características da pena. 2012. Disponível em: $\langle$ http://pt.scribd.com/doc/53004857/Caracteristicas-da-pena\#scribd〉. Acesso em: or mai.2019.

BUENO, Silveira. Minidicionário da língua portuguesa. São Paulo: FTD, 200

CALDAS, Gabriel Aparecido Anizio; CARLES, Fabiana David. Direitos humanos fundamentais e o princípio da individualização da pena no Estado democrático de direito. Anais do XVIII Congresso Nacional do CONPEDI, São Paulo - SP, novembro de 2009. 
BRASIL Código Penal <http://www.planalto.gov.br/ccivil_03/decretolei/del2848compilado.htm >Acesso em or mai.2org.

COSTA, Lídia Mendes da; AMARAL, Marilda Ruiz Andrade. A Superlotação do Sistema Prisional Brasileiro. Disponível em:< http://intertemas.unitoledo.br/revista/ index.php/ETIC/article/viewFile/ı677/ı6oo>. Acesso em: 24 dez. 2018.

Departamento de Execução Penal. Disponível em: http://www.depen.pr.gov.br/arquiv os/File/planoedu.pdf Acesso em :or de mai. de 2019

Dicionário Aurélio < https://www.dicio.com.br/prisao/> Acesso em 30 abr. 2019.

MIRABETE,Julio Fabrini. Processo Penal.i4.ed.rev.até dezembro de 2002.São Paulo:Atlas ,2003.p.359

OLIVEIRA, Odete Maria de. Prisão:um paradoxo social. 2. Ver.e.ampl.Florianópolis: Editora da UFSC,1996,p.233.

OTTOBONI, Mário. Ninguém é irrecuperável. 2. ed. São Paulo: Cidade Nova, 20oI

SENNA, Virdal. Sistema Penitenciário Brasileiro. fev. 2008. Disponível em:< http://www.webartigos.com/articles/4242/r/Sistema-Prisional/paginar.html>. Acesso em: 30 dez. 2018.

VIEIRA, Sebastião da Silva. Brarreto Campelo O olhar dos alunos: Detentos da penitenciária professor sobre a escola. Disponível em:< http://www.meuartigo.brasilescola.com/educacao/o-olhar-dosalunosdetentospenitenciaria-professor-.htm>. Acesso em: $30 \mathrm{dez}$. 2018 